\title{
معجم مصطلحات الإعاقة العقلية : إنجليزى - عربى
}

\author{
عرض و تقنييم \\ إيمان صلاح الدين محمد \\ كبير باحثين بدار الكتب و الوثائق مئق \\ القومية
}

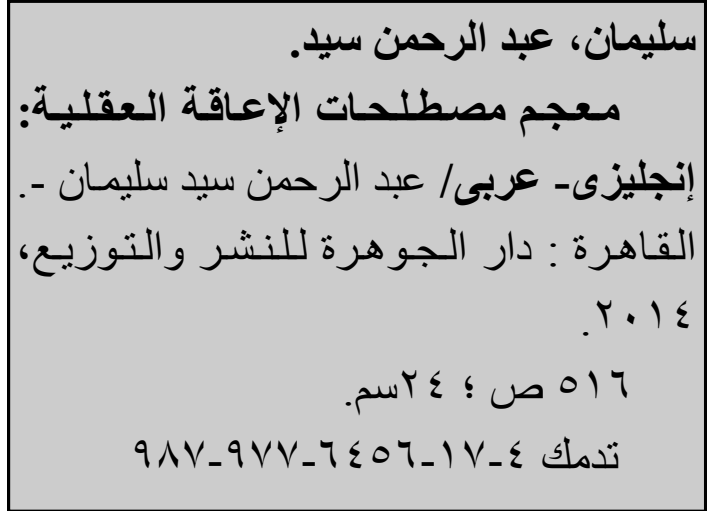

$9 \wedge V_{-} 9 \vee V_{-} 7 \varepsilon 0 \nearrow_{-} \mid \vee-\varepsilon$ تدمك

نظرًا لتقام المعارف العلمية وتخصصاتها ومانتج عن ذلك من مفاهيم ومصطلحات لم تكن

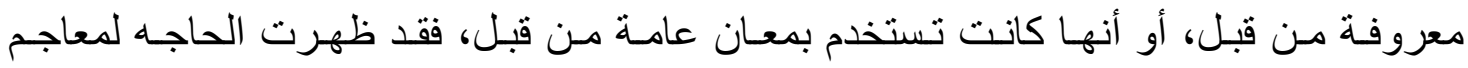

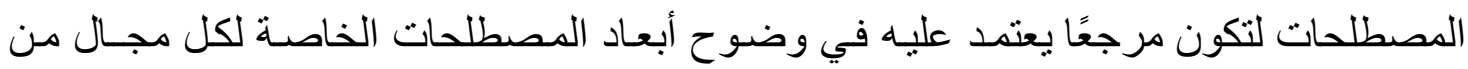

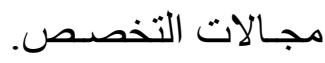

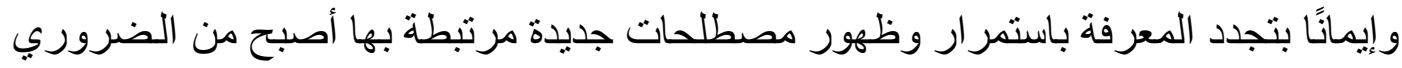

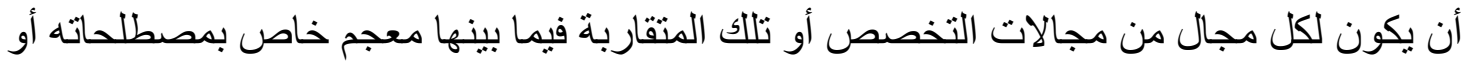

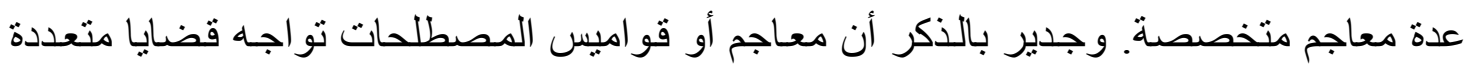

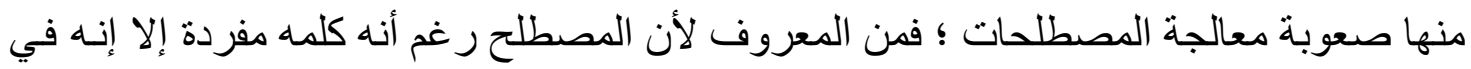
الوقت ذاته يحمل في مجمل حروفة دلالات متعددة .

وبتعدد المعاجم و القو اميس وتنو عها فهناك أكثر من أساس معتمد لتقسيمها ومنها ما يلي :

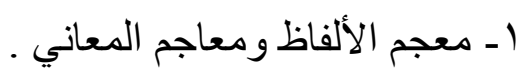

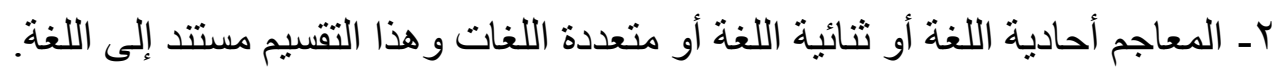

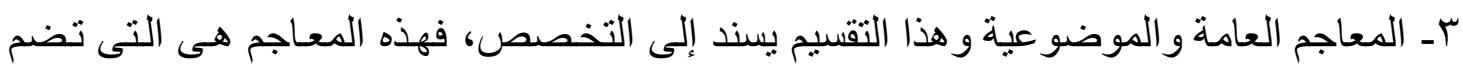

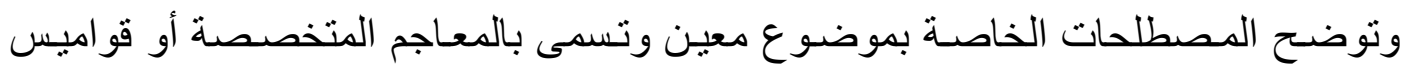

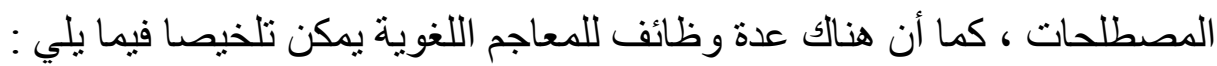
1 - المافظة على سلامة اللغة. 


$$
\begin{aligned}
& \text { r - إيجاد معاني الكلمات أو الكلمة ( و المعاني المختلفة للكلمة الو احدة). } \\
& \text { بـ معرفة أصل اللفظ و اشتقاقه. } \\
& \text { ــ الكثف عن معاني الألفاظ المجهولة و الغامضة. } \\
& \text { هـ معرفة كون اللفظة عامية أو فصيحة. } \\
& \text { 7ـ التحقق من معرفة المقاطع الهجائية أو علامات الوصل. } \\
& \text { V- الكثف عن معنى الكلمة في لغتين او أكثر. } \\
& \text { ^ـ معر فة معاني بعض الكلمات او المصطلحات المتخصصة. }
\end{aligned}
$$

أصبح من الأمور المستقرة الثابتـة في أذهان الأفر اد أن مصطلحات التربيـة الخاصـة يتـم

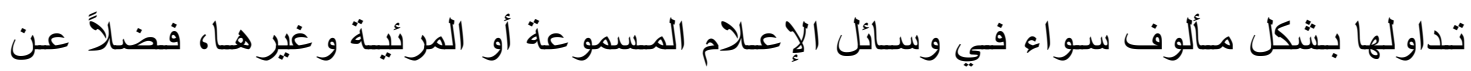

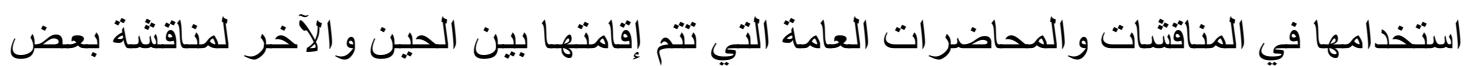

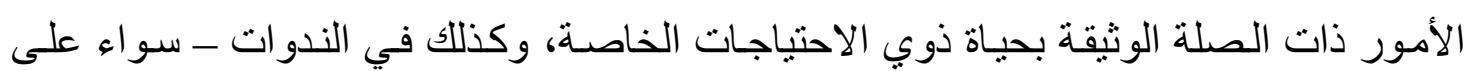

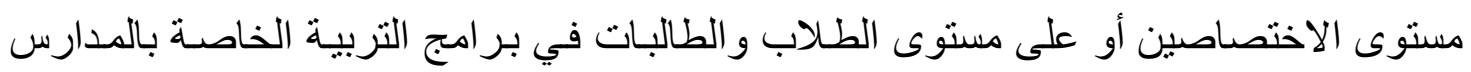
و المعاهد و المؤسسات على اختلاف أنو اعها وتباين اهتماماتها - وكذللك الجامعات مرورًا بآباء

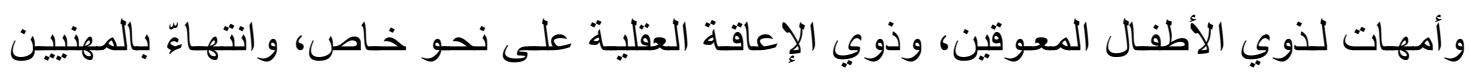

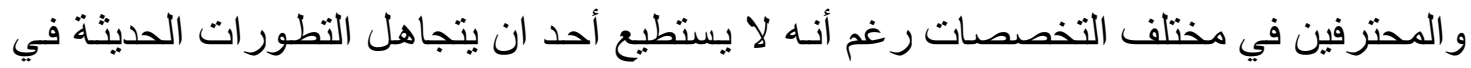

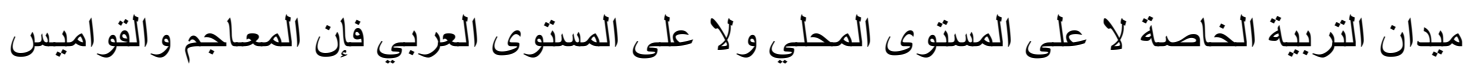

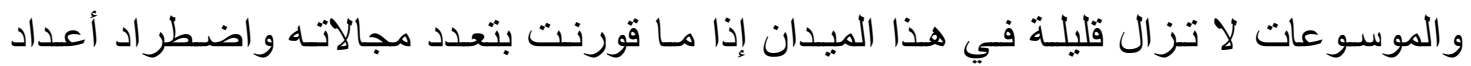

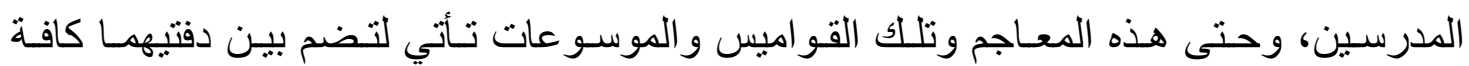

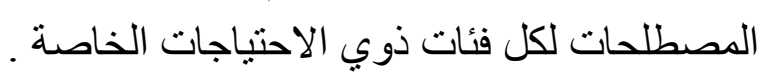

قام بإعداد هذا المعجم الأستاذ الدكتور عبد الرحمن سيد سليمان أستاذ ورئيس قسم التربيـة الخاصة بكلية التربية جامعة عين شمس، وحصل على الماجستير في الصحة النفسية من جامعة الصنة

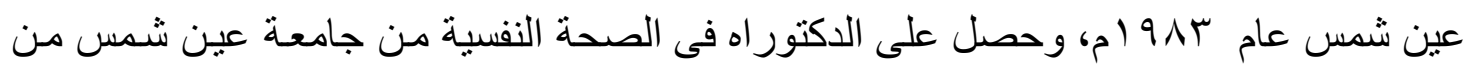

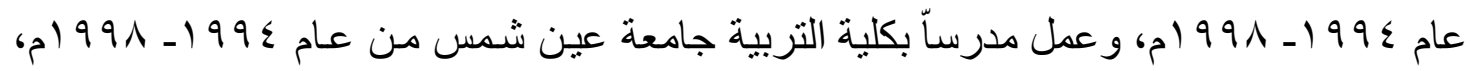

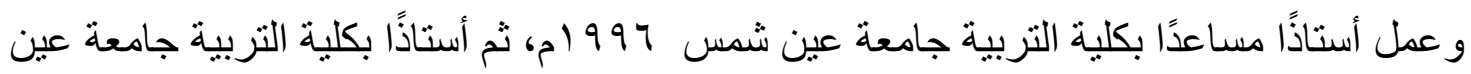

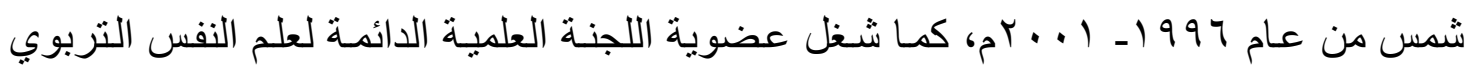

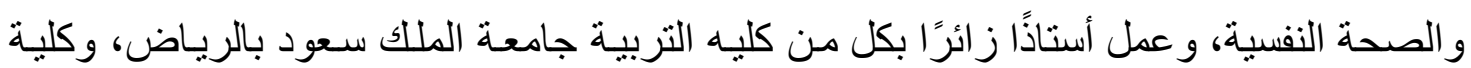
التربية بجامعة قطر بالدوحة.

يضم معجم مصطلحات الإعاقة العقلية إنجليزي - عربي بين دفتيه ما يزيد عن ( . . . 1) ألف 
مصطلح ؛ كلها تدور حول الإعاقة وذوي الإعاقة العقلية وأساليب ر عايتهم وطرق تربيتهم. تم تقسيم "معجم مصطلحات الإعاقة العقلية" إلى جزئين : الجزء الأول يعرض المصطلح فئحات بأحرف إنجليزية وفق ترتيبها الأجنبي المتعـارف عليه بحيث يستطيع مستخدم المعجم الذي يود

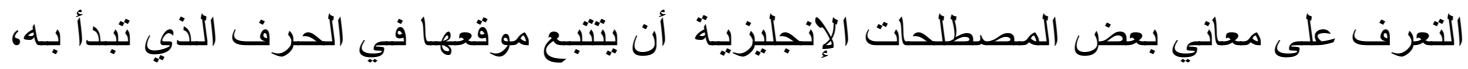

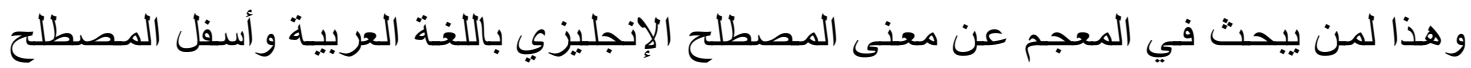
العربي تعريف لمعنى المصطلح. مثنال :

\section{Academic inventory}

أكاديمية. اختبار تحصيلي

مجمو عة من بنود الاختبار ، أو فقر اته يتم ترتيبها في سياق معين حسب صسوباتها، وتطبق

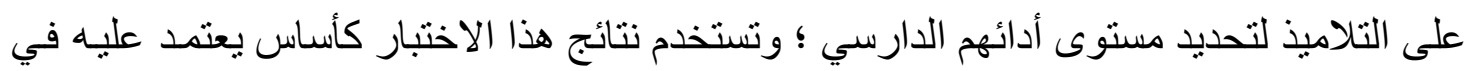
وضع الخطط الدر اسية لهؤلاء التلاميذ في المستقبل.

Academic underachivement.

انخفاض مستوى التحصيل الاراسي : و هو أن يكون مستوى التحصبل الدراسي للطفل أقل من المعدل الطبيعي المتعـارف عليه و الخاص بالعمر الزمني أو المرحلة الدر اسية التي ينتمي إليها الطفل.

\section{Acatolepsia Acatolepsia}

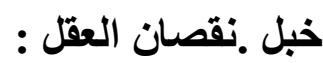
عدم القدرة على الفهم أو عدم القدرة على تعقل الأسباب، ويستخدم المصطلح كبديل لمصطلح

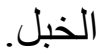

\section{Acatamothesia} عدم القدرة على فهم المدركات : غياب أو نقصان القدرة على فهم المدركات حول الموضو عات و المو اقف ويشير المصطلح أيضًا إلى عدم فهم الأحاديث.

\section{Acataphasia} صعوبة التعبيز اللغوي أكاتافيزيا : عدم القدرة على صياغة الكلمات في جمل مفهومة ذات معنى.

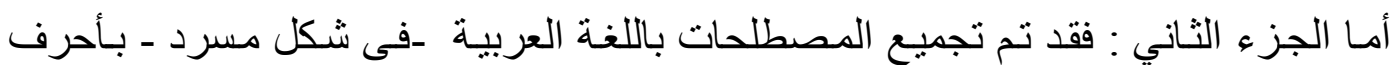
الأبجدية العربية وفق ترتيها المتعـارف عليه بحيث يستطيع المستخدم للمعجم الذي يود معرفة المقابل الأجنبي للمصطلح العربي أن يتتبعه في الحرف العربي الذي يبدأ به مثل :

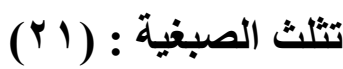


convulsive disorder

Borderline disorder

fndocrinism

Fructosemia

Genetie disorder

Metabolic disorders

thinking disorders

Conceptual disorders
اضطر ابات تثخيصية : اضطر ابات حدية : اضن

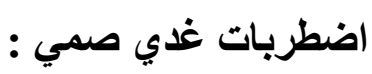

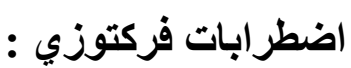

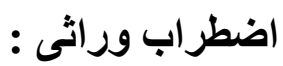

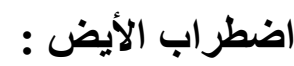

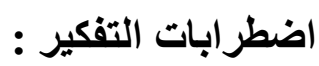

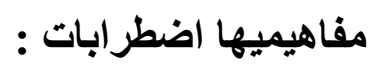
Specialchildren أطفال ذو احتياجات خاصة ؛ أطفال : وتوجد إحالات انظر من الجزء الإنجليزى إلى العربي منل :

Prevocational teacher معلم الإعداد المهني : المالان معلم مدرب على التنسيق بين الأنشطة المدرسية ومتطلبات العمل أو المهنة في مستوى

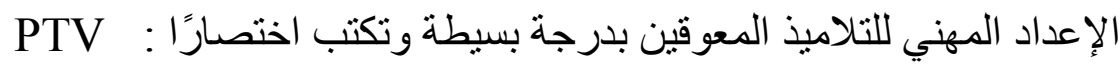
(Phprevocational level (انظر) : مستوى الإعداد المهني : Nonism

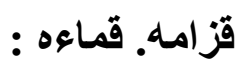

\section{Dwarfism}

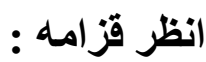

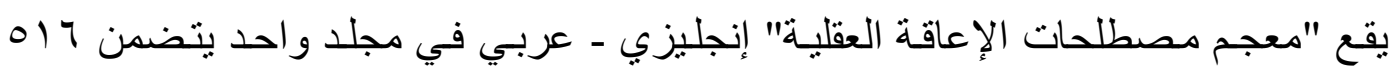

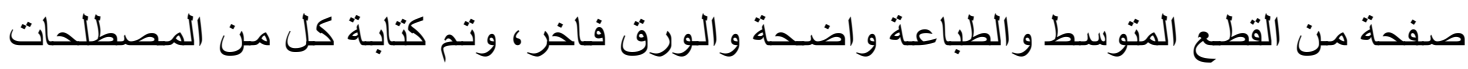

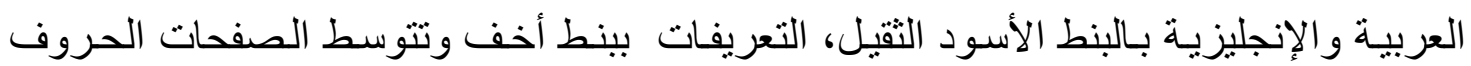
بالأبجدية الإنجليزية، و العربية بالبنط الأسود الكبير بين قوسين، و التجليد سميك وفيط وفاخر. ونأمل أن يكون هناك إضافة مقابلات للمصطلحات الإنجليزية بالفرنسية والألمانية و الإسبانية

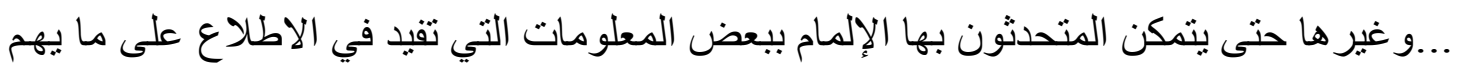

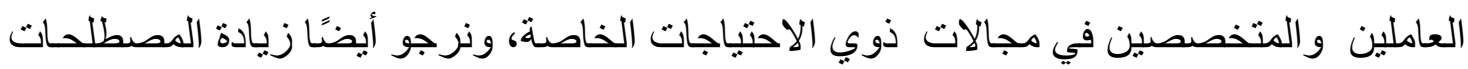

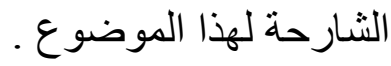

ويعد هذا المعجم أداة هامة للارسين و الباحثين و العاملين و المتخصصين في مجالات الإعاقة الإقة

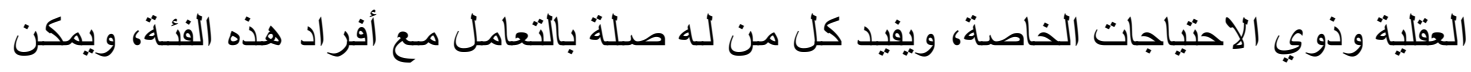

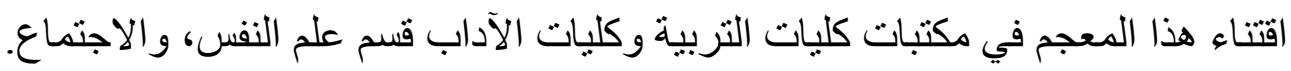

